\title{
Efecto antitumoral in vitro del aceite esencial de Piper aduncum L. (matico) y su toxicidad oral en ratones
}

Piper aduncum L. (matico) essential oil in vitro antitumoral effect and oral toxicity in mice

\author{
Jorge Arroyo ${ }^{1,2}$, Oscar Herrera-Calderón ${ }^{3,4}$, Roberto Chávez-Asmat ${ }^{2,5}$, \\ Edith Ventura ${ }^{6}$, Jesús Buendía ${ }^{6}$, José Pacheco ${ }^{6}$, Robert Palomino ${ }^{2}$ \\ Instituto de Investigaciones Clínicas, Facultad de Medicina, Universidad Nacional Mayor de San Marcos, Lima, Perú. \\ ${ }^{2}$ Laboratorio de Farmacologia, Facultad de Medicina, Universidad Nacional Mayor de San Marcos, Lima, Perú. \\ ${ }^{3}$ Facultad de Farmacia y Bioquímica, Universidad Nacional San Luis Gonzaga, Ica, Perú. \\ ${ }^{4}$ Unidad de Posgrado, Facultad de Farmacia y Bioquímica, Universidad Nacional Mayor de San Marcos, Lima, Perú. \\ ${ }^{5}$ Asociación para el Desarrollo de la Investigación Estudiantil en Ciencias de la Salud (ADIECS), Lima, Perú. \\ ${ }^{6}$ Facultad de Farmacia y Bioquímica, Universidad Nacional Mayor de San Marcos, Lima, Perú.
}

\begin{abstract}
Resumen
Introducción: Piper aduncum (matico) es una especie utilizada por sus propiedades medicinales en desórdenes gastrointestinales y genitourinarios. Objetivos: Evaluar el efecto antitumoral del aceite esencial de Piper aduncum (matico) in vitro en siete líneas celulares tumorales humanas y determinar la toxicidad oral en ratones. Diseño: Experimental. Institución: Facultad de Medicina, Universidad Nacional Mayor de San Marcos, Lima, Perú. Material biológico: Líneas celulares tumorales humanas H460, DU-145, ME-180, K562, HT-29, MCF 7, M14, K562; fibroblastos normales de ratón 3T3 y ratones albinos machos Balb/C53. Intervenciones: Las líneas celulares fueron expuestas a cuatro concentraciones del aceite esencial de $P$. aduncum y 5 -fluorouracilo (5-FU). Para la toxicidad oral se utilizó ratones albinos machos Balb $\mathrm{C} / 53$ de 40 dias post destete, a cinco dosis de tratamiento, evaluándose el número de muertes en cada dosis. Principales medidas de los resultados: Porcentaje de inhibición del crecimiento celular (IC50), dosis letal 50 (DL50). Resultados: El aceite esencial mostró IC50 mayor a $250 \mathrm{ug} / \mathrm{mL}$ para las líneas celulares M-14 $(r=-0,99 ; p<0,01)$, DU-145 $(r=0,99 ; p<0,01)$, ME-180 ( $r=-0,99 ; p<0,01)$. Para líneas celulares tumorales H460 ( $r=-0,99 ; p<0,01)$, MCF-7 $(r=-0,99 ; p<0,01), K 562(r=-0,99 ; p$ $<0,01)$, HT-29 $(r=-0,99 ; p<0,01)$, los niveles de IC50 estuvieron entre $20 \mathrm{ug} / \mathrm{mL}$ y $250 \mathrm{ug} / \mathrm{mL}$. DL50 $>2000 \mathrm{mg} / \mathrm{kg}$. Conclusiones: El aceite esencial de $P$. aduncum no presentó efecto antitumoral in vitro para las siete líneas celulares tumorales humanas y no fue tóxico.
\end{abstract}

Palabras clave: Aceite esencial; citotoxicidad; antitumoral; dosis letal, Piper aduncum, línea celular.

\begin{abstract}
Introduction: Piper aduncum (matico) is a medicinal plant used for gastrointestinal and genitourinary disorders. Objectives: To determine the in vitro antitumoral effect of Piper aduncum (matico) essential oil on seven human tumoral cell lines and its oral toxicity in mice. Design: Experimental. Setting: Faculty of Medicine, Universidad Nacional Mayor de San Marcos, Lima, Peru. Biologic material: Human tumoral cell lines HT-29, H-460, MCF-7, M-14, ME-180, DU-145, K-562; and 3T3 fibroblasts and male 40 days post weaning Balb C/53 mice. Interventions: The cell lines HT-29, H-460, MCF-7, M-14, ME-180, DU-145, K-562, and 3T3 were exposed to four different concentrations of Piper aduncum essential oil, and to different 5 -fluorouracil concentrations used as a positive control. Cell lines growth inhibition (IC50) was determined using linear regression analysis and DL50 by the number of deaths with each dose. Main outcome measures: Antitumor effect. Results: Piper aduncum essential oil showed cytotoxic activity at IC50 levels $>250 \mathrm{ug} / \mathrm{mL}$ on cell lines M-14 $(r=-0.99 ; p<0.01)$, DU-145 ( $r=-0.99 ; p<0.01), \mathrm{ME}-180(r=-0.99 ; p<0.01)$. IC50 was between $20 \mathrm{ug} / \mathrm{mL}$ and $250 \mathrm{ug} / \mathrm{mL}$ on cell lines H-460 $(r=-0.99 ; p<0.01)$, MCF-7, $(r=-0.99 ; p<0.01), K 562(r=-0.99 ; p<0.01), H T-29(r=-0.99 ; p<0.01)$. DL50 was $>2000 \mathrm{mg} /$ kg. Conclusions: $P$. aduncum essential oil did not show antitumoral effect on seven human tumoral cell lines and it was non toxic.

Keywords: Essential oil; cytotoxicity; antitumoral effect; lethal toxicity; Piper aduncum; cell lines.
\end{abstract}

An Fac med. 2014;75(1):13-8

\section{INTRODUCCIÓN}

El cáncer es uno de los problemas más crecientes en la salud pública y es la segunda causa de muerte después de las enfermedades cardiovasculares ${ }^{(1)}$.

De acuerdo con un reporte reciente de la Organización Mundial de la Salud (OMS), en el año 2005, de un total de 58 millones de muertes en todo el mundo, el cáncer representó el 13\% de muertes. Existen más de 10 millones de casos de cáncer por año en el mundo. La forma racional de combatir la carcinogénesis sería interfiriendo con la modulación de sus etapas (iniciación, promoción y progresión), así como las rutas de señalización celular. Hay nu- merosos carcinógenos bioquímicos y fisiológicos, como por ejemplo el asbesto y humo de cigarro ${ }^{(2,3)}$, infecciones por virus (ej. hepatitis $B$, virus que causa cáncer de hígado y el virus del papiloma humano que causa cáncer de cuello uterino) ${ }^{(4,5)}$; infecciones por bacterias (Helicobacter pylori causante de cáncer de estómago) ${ }^{(6)}$; infestaciones por 
parásitos (eschistosomiasis causante de cáncer de vejiga) ${ }^{(7)}$; y la contaminación de alimentos por micotoxinas (ej. las aflatoxinas causan cáncer de hígado) ${ }^{(8)}$. Algunos tipos de cáncer son producidos por especies radicalarias y otras especies oxigenadas que producen daño a las biomoléculas (ej. lípidos, proteínas, $\mathrm{ADN})^{(9)}$.

Piper aduncum L. es conocido popularmente como matico. Es un arbusto perenne que desarrolla más de 5 metros de altura, nativa del Caribe, aunque se ha adaptado a varios trópicos. El aceite esencial presenta una amplia variedad de usos tradicionales, como molusquicida, insecticida y antibacteriano ${ }^{(10,11)}$. El té elaborado de las hojas y raíces es usado para tratar la diarrea, disentería, náuseas, úlceras, infecciones del aparato urinario y trastornos hemorrági$\cos ^{(12)}$.

Se ha investigado los efectos del óxido de $\beta$-cariofileno $(\mathrm{CPO})$, un sesquiterpeno aislado a partir de aceites esenciales de plantas medicinales como pimienta negra (Piper nigrum L.), sobre las vías de señalización PI3K/AKT/ mTOR/S6K1 y MAPK, en el cáncer de próstata humano y las células de cáncer de mama, encontrándose que el $\mathrm{CPO}$ no solo inhibe la cascada de señalización constitutiva de PI3K/AKT/ mTOR/S6K1, sino también provoca la activación de ERK, JNK y p38 MAPK en las células tumorales; puede potenciar los efectos apoptóticos en las células tumorales de diversos inhibidores de PI3K/Akt farmacológicos, cuando se le emplea en combinación. En general, estos hallazgos sugieren que el $\mathrm{CPO}$ puede interferir con múltiples cascadas de señalización implicadas en la tumorogénesis y se le utiliza como un candidato potencial terapéutico para la prevención y el tratamiento del cáncer ${ }^{(13)}$. Los conocimientos etnomédicos hacen posible la investigación de plantas medicinales con propiedades antitumorales, para identificar posteriormente sus sustancias activas y desde allí nuevos fármacos efectivos contra el cáncer ${ }^{(14)}$. El presente estudio tuvo por objetivo evaluar el efecto antitumoral del aceite esencial de Piper aduncum (matico) in vitro sobre siete líneas celulares tumorales humanas y determinar la toxicidad oral en ratones.

\section{MÉTODOS}

Estudio experimental realizado en los laboratorios del Departamento de Farmacología de la Universidad Nacional Mayor de San Marcos (UNMSM) y en los Laboratorios de Investigación y Desarrollo "Abraham Vaisberg Wolach" de la Universidad Peruana Cayetano Heredia $(\mathrm{UPCH})$.

La unidad experimental fue cada célula perteneciente a las líneas celulares humanas HT-29 (adenocarcinoma de colon), H-460 (carcinoma pulmonar tipo células no pequeñas), MCF-7 (adenocarcinoma de mama), M-14 (melanoma amelanótico), ME-180 (carcinoma de cérvix), DU-145 (carcinoma de próstata), K-562 (leucemia mieloide crónica) y 3T3 (fibroblastos normales de ratón), proporcionados por los Laboratorios de Investigación de la UPCH.

Para la obtención de la muestra vegetal, las hojas de Piper aduncum $\mathrm{L}$. (matico) fueron colectadas en la ciudad de La Merced, Junín, sobre los 800 m.s.n.m.; fueron limpiadas con cuidado y estabilizadas. Para la estabilización, se las colocó en bolsas plásticas, añadiéndose gotas de alcohol etílico de 96\%; se cerró la bolsa y se agitó. La especie fue identificada taxonómicamente en el museo de Historia Natural de la UNMSM. Las hojas fueron desecadas bajo sombra, a temperatura ambiente (aproximadamente $21^{\circ} \mathrm{C}$ ), en los ambientes del Laboratorio de Farmacología de la Facultad de Medicina Humana de la UNMSM, durante 7 días, hasta obtener una muestra seca que fácilmente fue triturada; luego, se las conservó en bolsas de papel kraft hasta su utilización. Para la obtención del aceite esencial ${ }^{(15)}$, se sometió $10 \mathrm{~kg}$ de hojas secas de la muestra a destilación, por el método de arrastre por vapor de agua en un equipo de destilación de acero inoxidable, facilitado por el Laboratorio de Farmacognosia de la Facultad de Farmacia y Bioquímica de la UNMSM. El destilado se separó tomando en cuenta sus propiedades de inmiscibilidad y diferencia de densidades entre el agua y el aceite esencial, utilizando una pera de separación de vidrio; se deshidrató las impurezas de agua en el aceite esencial con sulfato de sodio anhidro, se filtró, guardándose en un frasco de vidrio color ámbar, bajo refrigeración a una temperatura de $4^{\circ} \mathrm{C}$.

El ensayo de la actividad antitumoral se desarrolló en el Laboratorio de Biología Celular y Virología de LID. UPCH. Las líneas celulares H-460 y DU-145 fueron cultivadas y mantenidas en crecimiento logarítmico en el medio de cultivo MEM (minimum essential medium) suplementado con $10 \%$ de suero bovino fetal y $50 \mu \mathrm{g} / \mathrm{mL}$ de gentamicina; asimismo, las líneas celulares MCF-7, M-14, ME-180, HT-29 y K-562 en el medio de cultivo RPMI 1640, suplementado con $10 \%$ de suero bovino fetal y $50 \mu \mathrm{g} / \mathrm{mL}$ de gentamicina.

Finalmente, la línea celular 3T3 creció en el medio de cultivo DMEM (Dulbecco modified eagle medium). Todas las líneas fueron mantenidas a una temperatura de $37^{\circ} \mathrm{C}$, en un ambiente húmedo, con $95 \%$ de aire y $5 \%$ de $\mathrm{CO}_{2}$. Para resuspender cada línea celular, se lavó la monocapa de células con 3 x 4 $\mathrm{mL}$ de la solución de Hanks sin Ca-Mg. Luego, se agregó $1 \mathrm{~mL}$ de la solución de tripsina-EDTA, que después de diez segundos fue eliminada. Se incubó el frasco invertido por ocho minutos, a 37 ${ }^{\circ} \mathrm{C}$, al término de los cuales los cultivos fueron resuspendidos en $2 \mathrm{~mL}$ de cada medio de cultivo. En el caso de la línea K-562 no se utilizó este método, porque las células crecen en suspensión. Luego, se contó las células usando un hemocitómetro. Cada pozo de una placa de 96 pozos recibió $160 \mu \mathrm{L}$ de medio, conteniendo un número determinado de células previamente cuantificado.

Para el ensayo de citotoxicidad se utilizó una placa 0 (control), asignándose seis pozos para cada línea celular y 
Tabla 1. Diluciones del aceite esencial de Piper aduncum L. y 5-fluorouracilo.

\begin{tabular}{cccc} 
& Piper aduncum $\mathrm{L}$. & & Control positivo \\
\cline { 2 - 2 } Diluciones & $\begin{array}{c}\text { Aceite esencial (hojas) } \\
\text { ug/mL }\end{array}$ & 5-fluorouracilo (5-FU) \\
1 & 250,0 & ug/mL \\
2 & 62,50 & 15,63 \\
3 & 15,63 & 31,25 \\
4 & 3,91 & 0,98 \\
\hline
\end{tabular}

una placa 1 (experimental) con 12 pozos para cada línea celular. En cada pozo de ambas placas se colocó $160 \mu \mathrm{L}$ de medio de cultivo conteniendo las células. Se incubó a $37^{\circ} \mathrm{C}$ en una atmósfera húmeda con $5 \%$ de $\mathrm{CO} 2$ y $95 \%$ de aire, por 24 horas. A la placa 0 se le añadió ácido tricloroacético (TCA) para fijar las células y luego cuantificarlas en el tiempo cero. A la placa 1 se le agregó las diferentes diluciones de aceite esencial de Piper aduncum L. (matico) y de 5-fluorouracilo (5-FU), que se muestra en la tabla 1.

Para la evaluación de la actividad antitumoral, se empleó el método del bioensayo de citotoxicidad con sulforodamina B (SRB) descrito por Skehan y col. (1990) ${ }^{(16)}$. El ensayo se detuvo añadiendo ácido tricloroacético (TCA) a las placas. Las células fijadas con el TCA fueron teñidas por 20 minutos con una solución de SRB al 0,4\% en ácido acético al $1 \%$. El SRB no unido a proteínas fue removido con un lavado de ácido acético al 1\%. Luego de secar las placas, el SRB unido a las proteínas fue solubilizado con una solución $10 \mathrm{mM}$ de tris base (tris (hidroximetil)aminometano) ( $\mathrm{pH} \mathrm{10,5)} \mathrm{y} \mathrm{la} \mathrm{absorbancia} \mathrm{a}$ $450 \mathrm{~nm}$ fue leída en una lectora de microplacas. Para la línea K-562 se utilizó conteo directo, mediante el contador Coulter. La concentración inhibitoria de crecimiento 50 (CI50) se halló mediante el análisis de regresión lineal. Luego se determinó los coeficientes de correlación de Pearson (r), que nos indicó la relación dosis-respuesta entre las concentraciones y el porcentaje de crecimiento. Para determinar la selectividad citotóxica de las sustancias evaluadas, se calculó el índice de selectividad, según la fórmula CI50 de la línea control / CI50 de la línea tumoral. Si el valor era $>1$, indicaba que la sustancia era más citotóxica para las células tumorales que para las células normales; si era $<1$, significaba lo contrario. Se usó Microsoft Office Excel 2010 para crear la base de datos y efectuar los cálculos estadísticos.

Para la determinación de la dosis letal 50 (DL50) ${ }^{(17)}$, se utilizó ratones machos cepa Balb C/53 ( $=30)$ adquiridos del Instituto Nacional de Salud, con peso promedio de $24 \pm 1 \mathrm{~g}$ al inicio del experimento, mantenidos en un ambiente a temperatura de $20 \pm 2 \stackrel{\circ}{ } \mathrm{C}$, con un ciclo de luz/oscuridad de 12/12 h, en el Bioterio de la Facultad de Medicina de la UNMSM. Recibieron alimentación balanceada y agua ad libitum. Los animales fueron distribuidos aleatoriamente en 5 grupos de seis animales cada uno: Grupo 1: Control: SSF $10 \mathrm{~mL} / \mathrm{kg}$; Grupo 2: P. aduncum a 100 $\mathrm{mg} / \mathrm{kg}$; Grupo 3: P. aduncum a $500 \mathrm{mg} /$ kg; Grupo 4: P. aduncum a 1000 mg/kg; Grupo 5: P. aduncum a $2000 \mathrm{mg} / \mathrm{kg}$.

La administración de P. aduncum fue por vía oral. Los animales fueron observados constantemente durante las primeras $24 \mathrm{~h}$, continuando la misma diariamente durante un período de 14 días, registrando cualquier síntoma tóxico que pudiere presentarse.

\section{RESULTADOS}

Con respecto a los valores de CI50 del aceite esencial de Piper aduncum, así como del control 5-fluorouracilo en las líneas celulares tumorales estudiadas, se encontró para el aceite esencial CI50 mayores a $250 \mathrm{ug} / \mathrm{mL}$ en las líneas celulares M-14, DU-145, ME-180, que fue la mayor concentración utilizada en el bioensayo, no evidenciándose citotoxicidad. Por el contrario, mostró actividad citotóxica leve, en la línea celular tumoral H460, MCF-7, K562, HT-29 $(\mathrm{CI} 50<250 \mathrm{ug} / \mathrm{mL})($ tabla 2$)$.

En la línea celular H460 se apreció una leve actividad citotóxica en com-

Tabla 2. Valores de Cl50 y citotoxicidad del aceite esencial de Piper aduncum L. y 5- fluorouracilo en células tumorales y normales.

\begin{tabular}{|c|c|c|c|c|c|c|c|c|}
\hline \multirow{3}{*}{$\begin{array}{l}\text { Sustancias } \\
\text { citotóxicas }\end{array}$} & \multicolumn{8}{|c|}{ Valores de Cl 50 (ug/mL) † } \\
\hline & \multicolumn{7}{|c|}{$\begin{array}{c}\text { Células } \\
\text { tumorales }\end{array}$} & \multirow{2}{*}{$\begin{array}{c}\begin{array}{c}\text { Células } \\
\text { normales }\end{array} \\
3 \mathrm{~T} 3\end{array}$} \\
\hline & MCF-7 & K-562 & HT-29 & $\mathrm{H}-460$ & M-14 & DU-145 & ME-180 & \\
\hline Aceite esencial & $\begin{array}{l}114,81 \\
\pm 0,89\end{array}$ & $\begin{array}{r}194,54 \\
\pm 1,98\end{array}$ & $\begin{array}{l}152,58 \\
\pm 2,69\end{array}$ & $\begin{array}{c}48,30 \\
\pm 1,15\end{array}$ & $>250$ & $>250$ & $>250$ & $\begin{array}{l}65,55 \\
\pm 2,14\end{array}$ \\
\hline Control & - & - & - & - & - & - & - & - \\
\hline $5-\mathrm{FU}^{*}$ & $\begin{array}{l}0,645 \\
\pm 0,05\end{array}$ & $\begin{array}{c}4,08 \\
\pm 0,54\end{array}$ & $\begin{array}{c}0,33 \\
\pm 0,01\end{array}$ & $\begin{array}{c}0,35 \\
\pm 0,02\end{array}$ & $\begin{array}{c}1,17 \\
\pm 0,09\end{array}$ & $>15,63$ & $\begin{array}{c}0,27 \\
\pm 0,01\end{array}$ & $<0,24$ \\
\hline
\end{tabular}

Valores expresados en promedio y desviación estándar. † Concentración inhibitoria 50, * 5 -fluorouracilo. 
paración con las otras líneas tumorales; sin embargo, su citotoxicidad fue menor en comparación al 5-fluorouracilo para la línea control 3T3 (figuras 1 y 2).

Los índices de selectividad del aceite esencial de Piper aduncum y el control 5-fluorouracilo para las líneas celulares tumorales MCF-7, HT-29, K-562, PC-3, DU-145 y H-460 se muestran en la figura 3. En todos los casos los índices del aceite no superaron la unidad y estuvieron entre 0,26 y 0,57 , excepto para la línea tumoral $\mathrm{H} 460$. El 5-fluorouracilo alcanzó valores inferiores a la unidad en todas las líneas celulares. Estos datos muestran una baja seguridad del aceite y del 5-FU, al ser su citotoxicidad no selectiva para las líneas celulares tumorales. El grado de correlación de la relación dosis respuesta fue evaluado mediante el coeficiente de Pearson; los valores variaron entre $-0,99$ y $-0,99$ para el aceite esencial y entre $-0,98 \mathrm{y}$ $-0,99$ para el control 5-fluorouracilo. El aceite esencial y el control 5-fluorouracilo mostraron una relación dosis respuesta significativa $(\mathrm{p}<0,05)$ en todas las líneas celulares evaluadas en el bioensayo.

En la determinación de la toxicidad oral del aceite esencial de Piper aduncum (matico) administrado por vía oral en ratones, no se tuvo muertes hasta los quince días de observación y sin evidencia de cambios de relevancia clínica. La DL50 para el aceite esencial de Piper aduncum L. fue mayor a los $2000 \mathrm{mg} /$ $\mathrm{kg}$ de peso corporal, siendo clasificado según la OECD como no tóxico.

\section{DISCUSIÓN}

En América Latina, el género Piper tiene diferentes usos en la medicina tradicional y se ha comunicado diferentes actividades biológicas en los desórdenes gastrointestinales, ginecológicos, problemas de ansiedad, depresión, dolor, inflamación e infecciones bacterianas y fúngicas ${ }^{(18)}$. Sin embargo, pocos son los estudios científicos comprobados que se tienen hasta la actualidad.

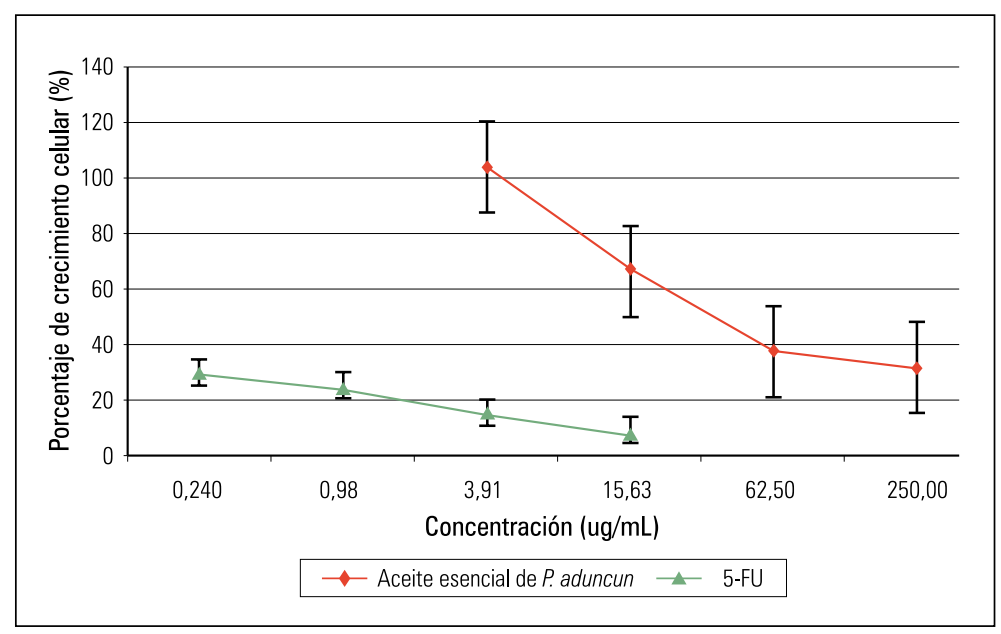

Figura 1. Porcentaje de inhibición del crecimiento de la línea celular 3Т3 (fibroblastos normales de ratón).

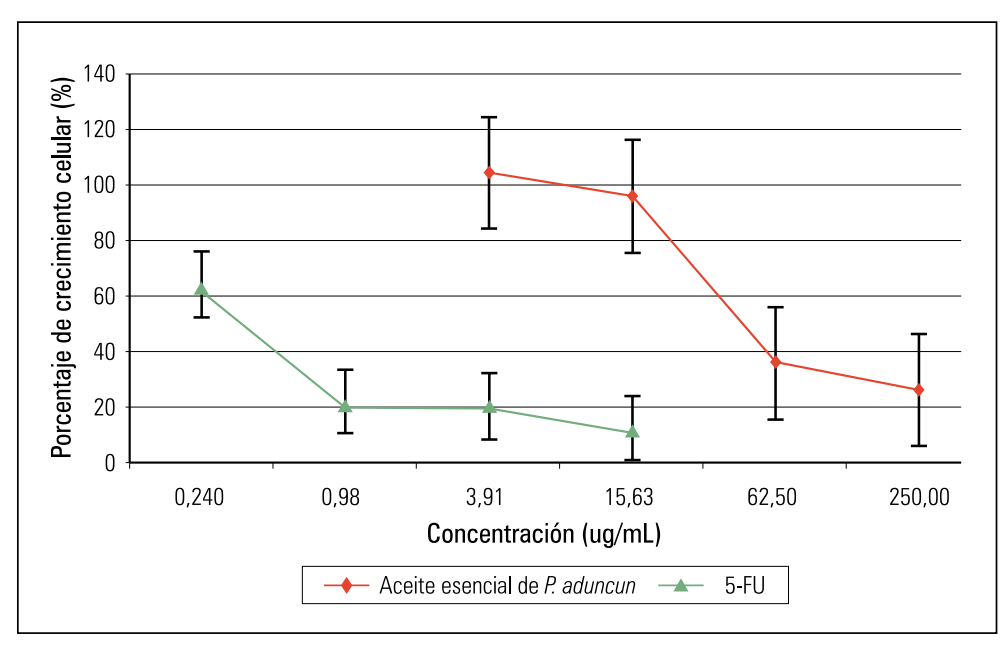

Figura 2. Porcentaje de inhibición del crecimiento de la línea celular H-460 (células de cáncer de pulmón tipo células no pequeñas).

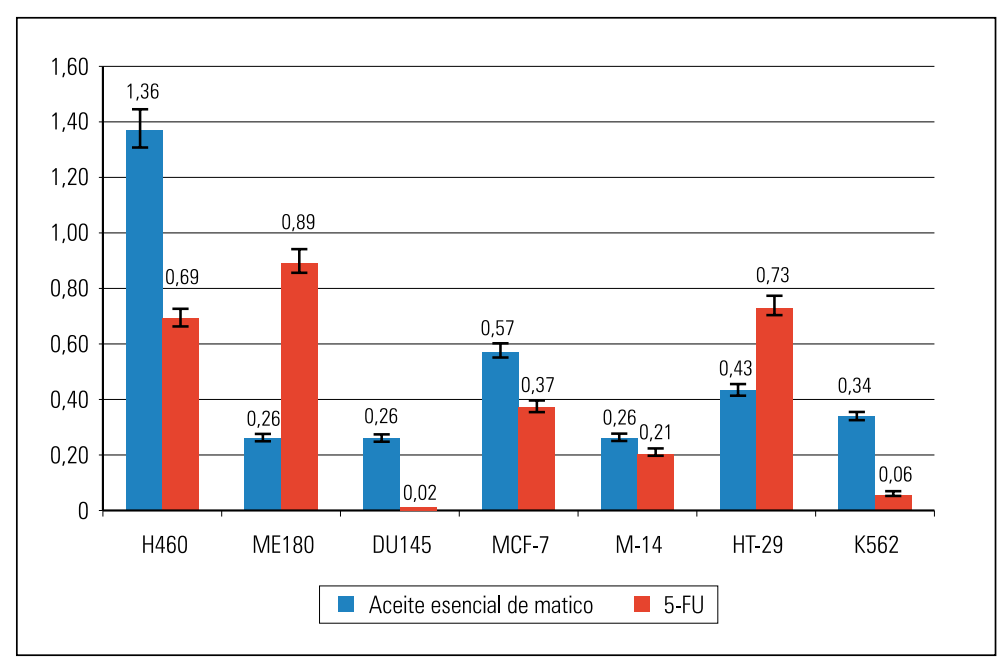

Figura 3. Índice de selectividad (I) del aceite esencial de Piper aduncum (matico) L y 5-fluorouracilo. 
Basándose en la Guía del Instituto Nacional del Cáncer de los Estados Unidos ${ }^{(19)}$, un extracto crudo es considerado que tiene actividad citotóxica in vitro si el valor de IC50 sobre las células tumorales, siguiendo una incubación entre 48 y 72 horas, es $\leq 20$ ug/ $\mathrm{mL}$, mientras que para un compuesto puro el valor de IC50 es $\leq 4 \mathrm{ug} / \mathrm{mL}$. El aceite esencial obtenido de las hojas de Piper aduncum no mostró actividad citotóxica frente a las siete líneas celulares tumorales evaluadas, excepto una mediana actividad para la línea tumoral H460 (IC50 = 48,30 $\pm 1,15)$, sin llegar a superar al 5-fluorouracilo (compuesto puro). Sin embargo, la citotoxicidad fue menor para las línea control 3T3 $(\mathrm{IC} 50=65,55 \pm 2,14)$.

En la determinación de los valores de la CI50 sobre las diferentes líneas celulares tumorales (tabla 2), observamos que los resultados se encuentran por debajo de otras especies del mismo género. Se ha informado que el extracto etanólico de Piper chabaes es citotóxico (IC50 $=18,63 \pm 5,03 \mu \mathrm{g} /$ $\mathrm{mL})$ para la línea tumoral carcinoma laríngeo (Hep-2), Piper pendulispicum $(\mathrm{IC} 50=64,94 \pm 5,78 ; 62,66 \pm 16,28$ $25,60 \pm 14,67)$ y Piper sarmentosum $(69,20 \pm 4,39 ; 81,95 \pm 10,79 ; 34,09$ $\pm 8,96)$ en las líneas celulares tumorales CL 6 (colangiocarcinoma), HepG2 (hepatocarcinoma), Hep-2 (carcinoma laríngeo), respectivamente ${ }^{(20)}$. Se plantea que el aceite esencial no presenta tal actividad por la ausencia de otros metabolitos no volátiles presentes en las hojas de P. aduncum, como son los compuestos fenólicos, flavonoides, alcaloides, taninos. De los estudios de Sakpakdeejaroen y col., la piperina es el componente activo de Piper chaba, que mostró actividad citotóxica sobre la línea celular tumoral MCF-7 (adenocarcinoma de mama), con un IC50 igual a $35,72 \mu \mathrm{M}^{(21)}$.

Los aceites esenciales y sus componentes volátiles individuales han despertado el interés de grupos de investigación en el cáncer. Un gran número de artículos son dedicados a la investigación de sus efectos contra una gran variedad de líneas celulares. De Sousa y col. (22) identificaron que el aceite esencial de Melissa officinalis L. mostró actividad citotóxica contra algunas líneas celulares tumorales (A549, MCF-7, Caco-2, HL-60, y K562). La citoxicidad de los aceites esenciales podría deberse a la presencia de algunos monoterpenos y sesquiterpenos, incluyendo el $\alpha$-humuleno ${ }^{(23)}$ e isoprenoides, incluyendo el geraniol. Sin embargo, el mecanismo de acción de sus componentes aún no está dilucidado del todo.

Las especies Piper guineense, Piper nigrum, Piper umbellatum y Piper caninum ${ }^{(24,25)}$ han mostrado tener propiedades antioxidantes y citotóxicas y un alto contenido de compuestos fenólicos, pero no se pudo demostrar la relación de los compuestos fenólicos presentes con su actividad citotóxica. Sin embargo, se justifica tal actividad a la presencia de los alcaloides, pero que no tenían actividad antioxidante. Dos alcaloides, chabamida y chabamide $G$ aislados de $P$. chaba, mostraron una potente actividad citotóxica sobre la línea celular COLO-205 (adenocarcinoma de colon), con valores de IC50 de $3,10 \mu \mathrm{g} / \mathrm{mL}$ y $0,018 \mu \mathrm{g} / \mathrm{mL}$, respectivamente ${ }^{(26)}$, y Piperlongimina B aislado de Piper longum (27) inhibió la proliferación celular de la línea celular HL-60 (leucemia mieloide crónica); pero, no hay mención de su actividad antioxidante. El extracto etanólico de las hojas de Piper imperiale es activo frente a la línea celular MCF-7, con una IC50 igual a $18,6 \pm 1,2 \mathrm{ug} / \mathrm{mL}$, y es probable que la alta actividad citotóxica se deba a la gran cantidad de compuestos fenólicos, según las determinaciones realizadas ${ }^{(28)}$.

En otros estudios se encontró que $\alpha$-pineno, aislado de Schinus terebinthifolius Raddi, induce apoptosis y confiere protección antimetastásica en un modelo de melanoma. Por otra parte, se ha demostrado que $\alpha$-pineno, mientras actué solo, es inactivo contra la línea celular C32 (melanoma amelanótico humano) y ACHN (células de adenocarcinoma renal humano) y que puede actuar en sinergismo con otros com- ponentes antiproliferativos del aceite esencial ${ }^{(29)}$.

La composición del aceite esencial de P. aduncum varía de acuerdo al lugar de procedencia. En América, Sureste Asiático y Oceanía el componente mayoritario es el dillapiol (30 a 90\%), en Bolivia el 1,8 cineol (40\%), en Panamá el $\beta$-cariofileno y aromadendreno ${ }^{(12)}$. Aunque en el presente estudio no se determinó la composición química del aceite esencial, es muy probable que el Piper aduncum que se desarrolla en Perú tiene composición variable en comparación con las otras regiones. Al presente no hay ensayos de citotoxidad realizados a Piper aduncum, ni como extracto o como aceite esencial, por lo que nuestro aporte sería un inicio para futuras investigaciones de cáncer en animales de experimentación.

En el ensayo de toxicidad oral, el aceite esencial administrado en ratones no evidenció muertes durante los 14 días de evaluación, a ningún nivel de dosis, según el protocolo empleado, y tampoco se observó daño a órganos, por lo que nuestros resultados se ajustan a lo encontrado por Castro y col. ${ }^{(30)}$. Sin embargo, esto difiere con el índice de seguridad (figura 3) comunicado en el ensayo in vitro de citotoxicidad a los fibroblastos normales de ratón 3T3. Es necesario realizar más estudios a nivel químico y farmacológico del aceite esencial de Piper aduncum que se desarrolla en nuestro país, por ser una especie promisoria en las diferentes patologías.

\section{REFERENCIAS BIBLIOGRÁFICAS}

1. Reddy L, Odhav B, Bhoola KD. Natural products for cancer prevention: a global perspective. Pharmacol Ther. 2003;99;1-13.

2. Surh YJ. Cancer chemoprevention with dietary phytochemicals. Nat Rev Cancer. 2003;3:76880.

3. Raposo CG, Carpeno JD, Baron MG. Causes of lung cancer: smoking, environmental tobacco smoke exposure, occupational and environmental exposures, and genetic predisposition. Med Clin. 2006; 128: 390-396.

4. Tabor E. Pathogenesis of hepatitis B virus-associated hepatocellular carcinoma. Hepatol Res. 2007; 37: S110-S114. 
5. Lee JY, Li JW, Yeung ES: Single-molecule detection of surface hybridized human papilloma virus DNA for quantitative clinical screening. Anal Chem. 2007;79:8083-9.

6. Shiotani A, lishi H, Uedo N, Ishiguro S, Tatsuta M, et al. Evidence that loss of sonic hedgehog is an indicator of Helicobater pylori-induced atrophic gastritis progressing to gastric cancer. Am J Gasteroenterol. 2005;100:581-7.

7. Vauhkonen $\mathrm{H}$, Bohling $\mathrm{T}$, Eissa $\mathrm{S}$, Shoman $\mathrm{S}$, Knuutila S. Can bladder adenocarcinomas be distinguished from schistosomiasis-associated bladder cancers by using array comparative genomic hybridization analysis? Cancer Genet Cytogen. 2007;177:153-7.

8. Groopman JD, Wang JS, Scholl P. Molecular biomarkers for aflatoxins: from adducts to gene mutations to human liver cancer. Can J Physiol Pharm. 1996;74:203-9.

9. Poulson HE, Prieme H, Loft S. Role of oxidative DNA damage in cancer initiation and promotion. Eur J Cancer Prev. 1998;71:9-16.

10. Araújo MJ, Câmara CA, Born FS, Moraes MM, Badji CA. Acaricide and repellent activity of essential oil of Piper aduncum its components against Tetranychusurticae. Exp Appl Acarol. 2012;57:139-55.

11. De Almeida RR, Souto RN, Bastos CN, da Silva MH, Maia JG. Variación quimica en Piper aduncum y propiedades biológicas de su dillapiole rico en aceite esencial. 2009;6(9):1427-34.

12. Guerrini A, Sacchetti T, Rossi D, Paganetto $T$, Muzzoli M, Andreotti E, et al. Bioactivities of Piper aduncum L. and Piper obliquum Ruiz \& Pavon (Piperaceae) essential oils of eastern Ecuador. Environ Toxicol Pharmacol. 2009;27:39-48.

13. Michel J, Duarte RE, Bolton JL, Huang Y, Caceres A, Veliz M, Soejarto DD, Mahady GB. Medical potential of plants used by the Q'eqchi Maya of Livingston, Guatemala for the treatment of women's health complaints. J Ethnopharmacol. 2007;114:92-101

14. Wang O, Liu S, Zou J, Lu L, Chen L. Anticancer activity of 2a, 3a, 19b, 23b-tetrahydroxyurs12-en-28-oic acid (THA), a novel triterpenoid isolated from Sinojackia sarcocarpa. PLoSONE. 2011;6(6):21130.
15. Rali T, Wossa SW, Leach DN, Waterman PG. Volatile chemical components $L$ and Piper gibbilimbum and Piper aduncum (Piperaceae) from Papua New Guinea. Molecules. 2007;12(3):389-94.

16. Skehan P, Storeng R, Scudiero D, Monks A, McMahon J, Vistica D, et al. New colorimetric cytotoxicity assay for anticancer drug screening. J Natl Cancer Inst. 1990;82(13):1107-12.

17. Lagarto A, Tillán J, Cabrera Y. Toxicidad aguda oral del extracto fluido de Mentha spicata L. (hierbabuena). Rev Cubana Plant Med. 1997;2(2-3):6-8.

18. Michel J, Duarte RE, Bolton JL, Huang Y, Caceres A, Veliz M, Soejarto DD, et al. Medical potential of plants used by the Q'eqchi Maya of Livingston, Guatemala for the treatment of women's health complaints. J Ethnopharmacol. 2007;114:92-101

19. Dahlawi H, Jordan-Mahy N, Clench MR, Le Maitre $\mathrm{CL}$. Shares bioactive extracts of pomegranate fruit in leukemia cell lines in vitro are promising for new therapeutic agents for leukemia. Nutr Cancer. 2012;64:100-10.

20. DeSouza MM, De Jesus RA, Cechinel-Filho V, Schlemper V. Analgesic profile of hydroalcoholic extract obtained from Marrubium vulgare. Phytomed. 1998;5(2):103-7.

21. Zarai Z, Kadri A, Chobba IB, Mansour RB, Bekir A, Mejdoub H, Néji G. The in-vitro evaluation of antibacterial, antifungal and cytotoxic properties of Marrubium vulgare L. essential oil grown in Tunisia. Lipids Health Dis. 2011;10:161.

22. De Sousa AC, Alviano DS, Blank AF, Alves PB, Alviano CS, Gattas CR. Melissa officinalis L. essential oil: antitumoral and antioxidant activities. J Agricult Food Chem. 2004;52(9):2485-9.

23. Salleh W, Ahmad F, Yen K, Sirat H. Chemical compositions, antioxidant and antimicrobial activities of essential oils of Piper caninum Blume. Int J Mol Sci. 2011;12:7720-31.

24. Agbor G, Vinson J, Oben J, Ngogang J. Comparative analysis of the in vitro antioxidant activity of white and black pepper. Nutr Res. 2006;26:659-63.

25. Tan LY, Yin WF, Chan KG. Piper nigrum, Piper betel and Gnetum-natural food sources with anti-quorum sensing properties. Sensors (Basel). 2013;13(3):3975-85.
26. Naz T, Mosaddik A, M Rahman, Muhammad I, Haque E, Cho SK. Compuestos antimicrobianos, antileishmanial y citotóxicos de Piper chava. 2012;26(11):979-86.

27. Mishra P, Sinha S, Guru S, Bhushan S, Vishwakarma R. Ghosal, S. Two new amides with cytotoxic activity from the fruits of Piper longum. J Asian Nat Prod Res. 2011;13:143-8.

28. Diaz LE, Muñoz DR, Prieto RE, Cuervo SA, Gonzalez DL, Guzman JD, et al. Antioxidant, antitubercular and cytotoxic activities of Piper imperiale. Molecules. 2012;17:4142-57; doi: 10.3390/ molecules17044142.

29. Loizzo MR, Tundis R, Menichini F, Saab AM, Statti GA, Menichini F. Antiproliferative effects of essential oils and their major constituents in human renal adenocarcinoma and amelanotic melanoma cells. Cell Prolif. 2008;41(6):1002-12.

30. Castro W, De Souza JR, Menezes HE, Heinzen H, Cesio MV, Mato M, et al. Toxicity of Piper aduncum L. (Piperales: Piperaceae) from the Amazon forest for the cattle tick Rhipicephalus (Boophilus) microplus (Acari: Ixodidae). Veterinary Parasitol. 2009;164:267-74.

Proyecto FEDU 2013

Articulo recibido el 9 de setiembre de 2013 y aceptado para publicación el 20 de diciembre de 2013.

Conflictos de intereses: Los autores expresan no tener algún conflicto de interés.

\section{Correspondencia:}

\section{Oscar Herrera Calderón}

Dirección: Campus universitario (Panamericana Sur Km 305 s/n) Universidad Nacional San Luis Gonzaga de Ica, Departamento Académico de Ciencias Farmacéuticas

Teléfono: 956550510

Correo electrónico: oh2000_4@hotmail.com 